\title{
Sendai virus-based liposomes enable targeted cytosolic delivery of nanoparticles in brain tumor-derived cells
}

\author{
Veronica Dudu, Veronica Rotari and Maribel Vazquez
}

\begin{abstract}
Background: Nanotechnology-based bioassays that detect the presence and/or absence of a combination of cell markers are increasingly used to identify stem or progenitor cells, assess cell heterogeneity, and evaluate tumor malignancy and/or chemoresistance. Delivery methods that enable nanoparticles to rapidly detect emerging, intracellular markers within cell clusters of biopsies will greatly aid in tumor characterization, analysis of functional state and development of treatment regimens.

Results: Experiments utilized the Sendai virus to achieve in vitro, cytosolic delivery of Quantum dots in cells cultured from Human brain tumors. Using fluorescence microscopy and Transmission Electron Microscopy, in vitro experiments illustrated that these virus-based liposomes decreased the amount of non-specifically endocytosed nanoparticles by $50 \%$ in the Human glioblastoma and medulloblastoma samples studied. Significantly, virus-based liposome delivery also facilitated targeted binding of Quantum dots to cytosolic Epidermal Growth Factor Receptor within cultured cells, focal to the early detection and characterization of malignant brain tumors.
\end{abstract}

Conclusions: These findings are the first to utilize the Sendai virus to achieve cytosolic, targeted intracellular binding of Qdots within Human brain tumor cells. The results are significant to the continued applicability of nanoparticles used for the molecular labeling of cancer cells to determine tumor heterogeneity, grade, and chemotherapeutic resistivity.

Keywords: Virus-based liposomes, Quantum dots, cancer, EGFR, Sendai Virus

\section{Background}

Nanoparticles have facilitated unprecedented study of biological processes and molecular markers within a variety of cell samples (reviewed in [1-4]). Diagnostic assays where nanoparticles are used to detect the presence and/ or absence of a combination of cell markers are becoming increasingly significant in the identification of progenitor or stem-like cells found within a variety of tumors [5]. While nanotechnology has pioneered major advances in cancer detection, diagnosis, and treatment [6], tumors within brain continue to pose one of the lowest survival rates five years after diagnosis [7]. While such poor prognosis is largely associated with the highly invasive nature of malignant brain tumors [8-10], the cellular

\footnotetext{
* Correspondence: Vazquez@ccny.cuny.edu

The City College of New York, Department of Biomedical Engineering, 160 Convent Avenue, New York, NY 10031, USA
}

heterogeneity of diseased brain also plays a large role, as constituent subpopulations of neoplastic cells with stemlike properties [11] appear to be resistant to conventional radiotherapy and chemotherapeutic regimens [12]. Emerging studies have underscored the significance of intracellular markers when identifying neoplastic stem-like populations (reviewed in [13]), either in tandem with existing extracellular markers (e.g. CD133, PAX6, reviewed in [14]) or alone. Numerous cytosolic molecules currently serve as therapeutic targets for radiosensitization, including heat shock proteins [15], binding proteins [16], Hypoxia Inducible Factors HIF1 and HIF2 [17], transcription factors [18], and phospholipoases [19]. In addition, recent studies point to cytosolic markers as excellent detectors of biochemical signatures from cells previously thought to evade the neural system, such as the prion-like protein Doppel $(\mathrm{Dpl})$ found in the male
C Biomed Central

(C) 2012 Dudu et al; licensee BioMed Central Ltd. This is an Open Access article distributed under the terms of the Creative Commons Attribution License (http://creativecommons.org/licenses/by/2.0), which permits unrestricted use, distribution, and reproduction in any medium, provided the original work is properly cited. 
reproductive system [20], and light neurofilament proteins and class III $\beta$-tubulin found in bone marrowderived mesenchymanl stem cells [21].

Labeling of intracellular molecules is notoriously difficult to achieve using nanoparticles because of the highly esoteric selectivity required [22]. Intracellular delivery of nanoparticles is strongly affected by both the nature of the particle and the type of cell examined (reviewed in [23]). For example, established delivery methods of bioconjugates, such as Quantum dots (Qdots), via endocytosis, pinocytosis and injection are known to alter cell function as well as exhibit varied effectiveness per cell type and/or experimental condition $[24,25]$. Further, alternative approaches such as electroporation [26], nanoneedles [27], and cell-penetrating peptides [28] have led to internalized Qdots that can become trapped within the endocytic pathway and/or form large aggregates in the cytoplasm [29]. Most recently, researchers have utilized cell penetrating peptides [30,31], $\mathrm{pH}-$ dependent fusogenic peptides [32], as well as logicembedded vectors [33] to achieve endosomal release after internalization. Others have minimized endosomal trapping by using silica [34], gold [35,36], and polymerbased nanoparticles [37] and polyactic acid [38], while yet others have disrupted endocytosis by using lightactivated disruption of intracellular vesicles [39], or controlled sub-cellular damage of endosomal structures [40].

Recent applications have revived the practice of nanoparticle encapsulation by incorporating nanoparticles within patented synthetic proteins and polymers, as well as within antiretroviral complexes [41], each with a varying degree of endosomal escape. Our group has previously shown that cationic liposomes are able to facilitate intracellular delivery of Qdots within live brain cancer cells [42], but demonstrated that the method is cell line-dependent: Liposomal delivery of Qdots was cytoplasmic within glioblastoma-derived cells, but resulted in endocytosis and trapping of liposomes within endosomes when HeLa cells were used. More unconventional approaches to nanoparticle delivery have begun to incorporate viruses previously used to deliver other nanosized molecules, such as DNA, synthetic oligonucleotides, and pharmaceuticals [43]. Chymeric bacteriophages have been employed to target tumors and introduce intracellular agents bound to its surface [44], while the plant mosaic virus [45] was used to incorporate Qdots coated with various molecules (e.g. streptavidin-biotin, dihydrolipoic acid) within its capsid. A recent study adapted the simian virus 40 capsid to encapsulate Qdots functionalized with different surface coatings (e.g. DNA, PEG) for transport within kidney cells [46]. While delivery was successful, it remained unclear whether the virus itself enabled cytosolic release of Qdots or if the Qdots remained trapped within cellular compartments [46].

The current study has achieved cytoplasmic delivery of targeted Qdots via chimeric fusions between the Sendai virus and cationic liposomes [47]. The Sendai virus is a mouse parainfluenza virus that has been safely used for over two decades, in vitro and in vivo, to deliver molecules such as plasmid DNAs, siRNAs, proteins, iron particles, and pharmaceuticals into numerous cell types (reviewed in [48]). Its role as a delivery vector capitalizes on two types of proteins present in its capsid: (i) Hemagglutinating and Neuraminidase (HN) proteins, used for attachment of the virus to neuraminic acid-containing receptors on host cells, hemagglutination of erythrocytes, and neuraminidase activity [49]; and (ii) Fusion (F) proteins needed for virus penetration of host cell membranes, virus-induced hemolysis, and cell fusion [49-51]. In this work we use the Sendai virus to generate virus-based liposomes that achieve cytosolic delivery of targeted Qdots into live Human brain tumor cells with high, consistent efficiency. Qdots were functionalized with a monoclonal biotinylated antibody (Ab) designed to specifically recognize an intracellular epitope of the Epidermal Growth Factor Receptor (EGFR). EGFR was chosen as a candidate target protein because its over-expression and up-regulation is recognized as a significant step in the pathogenesis and progression of a wide variety of cancers, including tumors of the brain [52-55]. Further, previous work from our laboratory has successfully labeled activated EGFR populations in live brain cancer cells by binding Qdots to the extracellular domain of EGFR and then inducing receptor activation to detect intracellular, activated EGFR [56]. In the current study, delivery of Qdot by chimeric fusions between the Sendai virus and cationic liposomes, henceforth called virus-based liposomes (VBLs), was assessed using three different Human cancer cell types: (i) Medulloblastoma (MB), the most common form of pediatric brain tumor; (ii) Glioblastoma (GBM), the most common form of tumor in adult brain; and (iii) HeLa cervical cancer, a well-studied cell line used here as an experimental control.

\section{Results and Discussion}

\section{Cellular EGFR Localization in Medulloblastoma}

In order to examine the targeted delivery of nanoparticles to cytosolic EGFR targets in MB, experiments first examined EGFR in MB cells during signaling events, with and without ligand stimulation. EGFR signaling is known to be tightly regulated by receptor endocytosis and lysosomemediated degradation [57]. In adult brain, the tumor suppressor gene, Mig-6, has been recently shown to quell the malignant potential of GBM and dampen EGFR signaling by driving EGFR into late endosomes and lysosomemediated degradation upon ligand stimulation [58]. 
In pediatric brain, EGFR signaling within more embryonal $\mathrm{MB}$ cells delineates a poorer outcome, and is believed to be a function of MB type and grade [52]. Early detection of such signaling is highly significant for MB patient prognosis, as $70 \%$ of children with elevated levels of EGFR expression succumb to their neoplastic disorder prior to 4 years of age [52].

Our first set of experiments examined EGFR localization within MB-derived cells by labeling the receptor with an antibody that recognizes the intracellular amino-acid sequence 985-996 of EFGR, henceforth referred to as iEGFR. This domain was chosen for experiments of targeted delivery so that Qdot binding would have minimal effects on EGFR phosphorylation and its subsequent recruitment of signaling adaptor proteins (see Methods). EGFR location was determined both by standard immunostaining using secondary fluorescence Alexa 488 detection (Figure 1A), as well as via nanoparticle complexes formed between biotinylated iEFGR Abs and Qdots (Figure 2B). Measured co-localizations of the receptor with the endocytic pathway via confocal microscopy (Figure 1A) illustrated that $43.1 \%+/-4.4 \%$ of EGFR was present within the endosomes of non-ligand stimulated MB cells when measured via conventional secondary antibodies, consistent with $36.2 \%+/-0.4 \%$ endosomal presence when measured via Qdots (Figure 1C).

These initial results are not only among the first to utilize Qdots to measure the cytosolic EGFR population in $\mathrm{MB}$, but additionally depict the EGFR population internalized within the endocytic compartments of these cells in the absence of tyrosine kinase activity [59]. These findings become critical to nanoparticle labeling of EGFR within MB, as increased endosomal EGFR signaling is being explored as a marker of de-differentiated cells that are linked to recurrence and radioresistivity in malignant brain tumors [52].

\section{Nanoparticle Cytosolic Delivery via Liposome-only and Virus-Based Liposomes}

Researchers have recently illustrated that nanoparticles conjugated to a drug or antibody cannot simply be internalized in order to bind cytosolic or endosomal targets, because the nanocomplexes can distinctly alter cellular processes at the molecular level [60]. As a result, the next set of experiments utilized VBLs to facilitate Qdot binding to cytosolic iEGFR in order to derive measurements of both the populations of native cytosolic EGFR and endosomal EGFR within MB samples. Here, we examined the in vitro, intracellular delivery of Qdots targeted to iEGFR via cationic liposomes alone, and by using VBLs. (Note that experiments do not seek to track the translocation of cytosolic EGFR proteins to endosomes during signaling). As shown in the schematics of Figure 2, when liposomes are used for intracellular delivery (Figure 2A1), Qdots can become internalized non-specifically within endocytic compartments (Figure 2A2) and remain trapped within liposomes, which are themselves trapped within the endocytic compartments of the cell (Figure 2A3). By contrast, when VBLs are used for intracellular delivery (Figure 2B1), functionalized Qdots can be released within the cytosol (Figure 2B2) and remain free to bind to their targets (Figure 2B3). A schematic of how the VBLs were generated (Figure 2C) helps to illustrate how VBLs can be selective for intracellular targeting. The cartoon includes TEM images of an inactivated virus (approximately $200 \mathrm{~nm}$ in diameter) as well as of a liposome (approximately $100 \mathrm{~nm}$
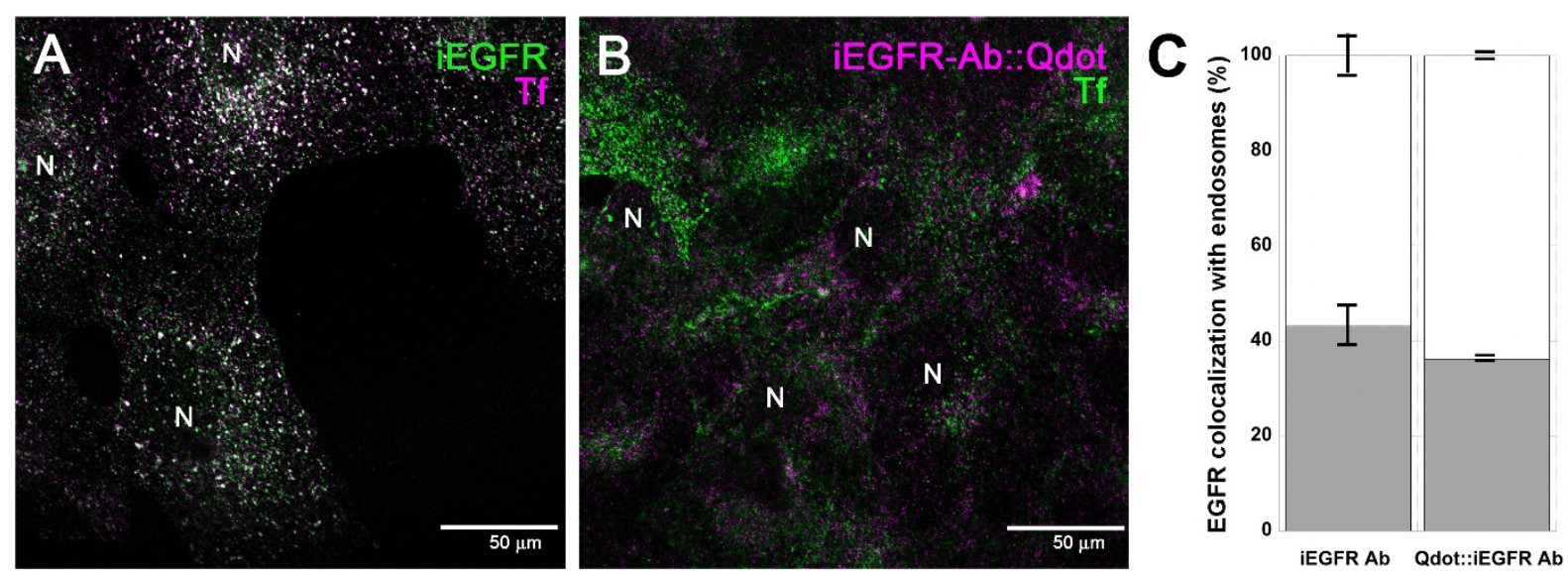

Figure 1 Immunostaining of intracellular EGFR in medulloblastoma. A. Labeling of EGFR using an antibody that recognizes an internal isotope, iEFGR (Alexa 488; green), and of the endocytic pathway using Transferrin (Tf) (purple) in medulloblastoma (MB) cells; B. Labeling of EGFR in MB using Qdots functionalized with biotinylated iEFGR (purple) and of the endocytic pathway using Tf (green); C. Percentage colocalization between Tf and iEGFR Ab, and Tf and Qdot:iEGFR Ab complexes. Nuclei are indicated by the letter "N". Scale bar equals 50 um in both confocal images. 


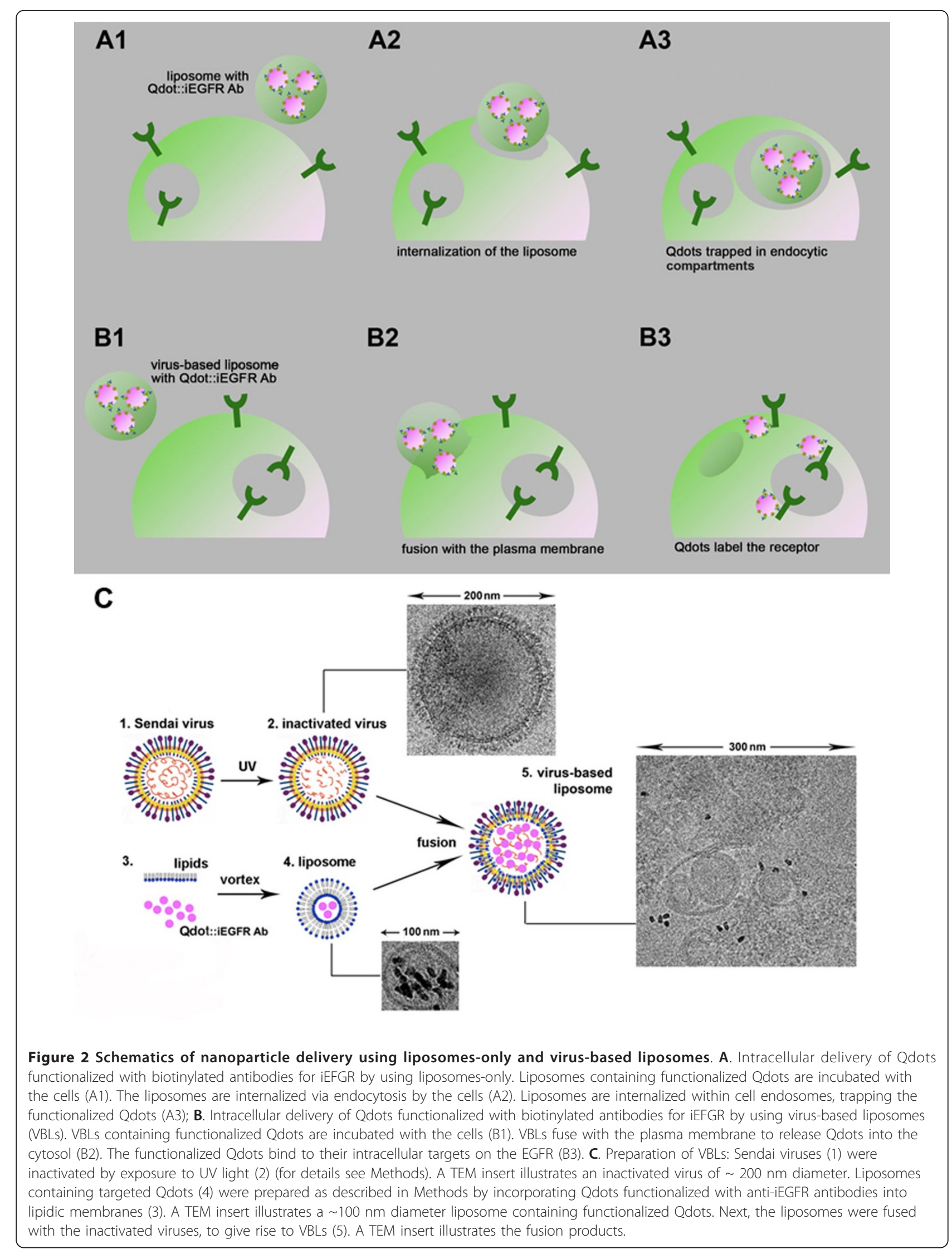


in diameter) that contains Qdots within its lipid membrane. Experiments used both liposomes-only and VBLs to deliver non-functionalized Qdots (i.e. without antibody conjugation) within GBM and HeLa cell samples. Note that experiments were used to measure the differences in cytosolic delivery when using VBLs versus liposomes alone within each cell type, individually. The data is not compared across different cell lines, which invariably have different levels of native EGFR expression. In both samples, the majority of the liposomes containing Qdots were trapped within endosomes as measured previously by our laboratory $[42,56]$ using Qdot-Tf co-localization via confocal microscopy: $56 \%+/-4.8 \%$ for GBM (Figures 3A and $3 \mathrm{C}$ ), and $80 \%+/-3.5 \%$ for HeLa (Figures 3D and 3F). Conversely, when VBLs were used, Qdots were distributed sparsely within the cytosol of GBM (Figure 3B) and HeLa cells (Figure 3E). Measurement of Qdot co-localization with Tf-labeled endosomes confirmed that $75 \%+/-1.9 \%$ of the Qdots were detected intracellularly and outside of the endosomes for GBM (Figure 3C), leaving only $25 \%+/$ $1.9 \%$ trapped in the endosomes. Similarly, $64 \%+/-4 \%$ of Qdots were detected outside of the endosomes of HeLa cells (Figure 3F), while 36\% +/- 4\% of Qdots were observed within the endosomes of these cells. Additional co-localization statistics were performed using Manders coefficients with values of 0.48 for GBM and 0.81 for
HeLa when liposomes-alone where used with Tf-labeled endosomes. When VBLs were used with Tf-labeled endosomes, Manders coefficient values of 0.72 for GBM and 0.59 for HeLa were tabulated. We note that while the concentration of Qdots delivered using liposomes-only appears higher than the concentration of Qdots delivered via VBLs, we believe this is due to the higher background noise of clustered Qdots endocytosed via the liposomesonly delivery.

Previous studies have utilized nanoparticles for the detection of markers within breast, prostate and lung $[61,62]$, but few have examined Qdot applications in malignant brain tumors [63]. The results of the present study document an increase of up to $50 \%$ in the number of intracellularly delivered Qdots that remain free to bind cytosolic targets within malignant brain tumors when compared to liposomes alone. Such dramatic increases will augment detection in numerous cancer diagnostic assays used to characterize the type, grade, and level of heterogeneity in tumors.

\section{Cytosolic Virus-based Liposome Delivery of Nanoparticles Targeted to iEGFR}

The final set of experiments utilized VBLs to deliver nanoparticles within live $\mathrm{MB}$ samples and to image the cellular location of the Qdot::iEGFR Ab complexes via
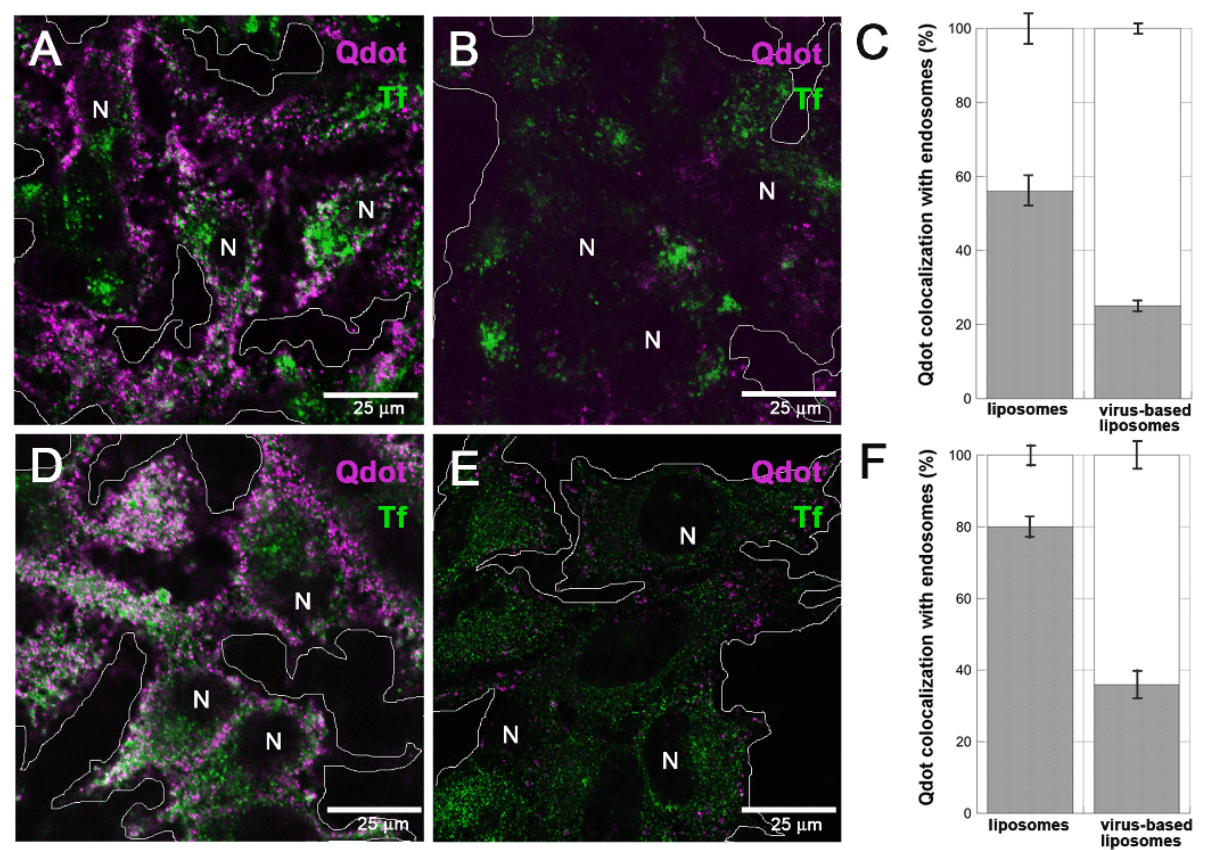

Figure 3 Intracellular delivery of Qdots using liposomes-only and virus-based liposomes in glioblastoma and HeLa cells. Cell nuclei are denoted by the letter " $\mathrm{N}$ " and endocytic pathways are labeled by Transferrin (Tf) (green). Scale bar equals $25 \mu \mathrm{m}$ in all confocal images. A. Double labeling of glioblastoma (GBM) cells for non-targeted Qdots delivered by using liposomes-only (purple). B. Double labeling of GBM cells for non-targeted Qdots delivered by using virus-based liposomes (VBLs) (purple). C. Measurement of Qdot co-localization with endosomes (black) and cell cytosol (white) when delivered by liposomes-only or VBLs in GBM; D. Double labeling of HeLa cells for non-targeted Qdots delivered by using liposomes-only (purple). E. Double labeling of HeLa cells for non-targeted Qdots delivered by using VBLs (purple). F. Measurement of Qdot co-localization with endosomes (black) and cell cytosol (white) when delivered by using liposomes-only and VBLs. 
confocal microscopy and/or TEM (Figure 4). When using liposomes-only as the delivery system, non-functionalized Qdots were detected within Tf-labeled endosomes (Figures 4A). Measurement of co-localized fluorescent signatures revealed that $56 \%+/-1.4 \%$ of Qdots were present within the cell endocytic pathway (Figure 4E). This data indicates that liposomes were predominantly internalized via endocytosis in $\mathrm{MB}$, as has been reported for other cell lines (reviewed in [64]). Moreover, TEM of MB samples treated with liposomes containing Qdot::iEGFR Ab complexes led to detection of the well-known electron-dense cores of the Qdots within the cell endocytic compartments (Figure 4B). In contrast, when Qdots were delivered using VBLs, confocal microscopy illustrated Qdots that were evenly distributed throughout the MB cytosol (Figures 4C). Measured localization of these Qdots revealed that only $30 \%+/-3.6 \%$ of the Qdot signal was present within the cell endosomes (Figure 4E). Note that Qdots located within the endosome are unlikely to bind iEGFR because they remain trapped within liposomal membranes, as previously shown [42]. However, the data do illustrate that VBLs released the majority of their cargo (i.e. $70 \%+/-3.7 \%$ ) into the cytosol of MB cells. Consistent Manders coefficients of 0.68 support this co-localization. In addition, TEM of the samples treated with VBLs containing functionalized Qdot::iEFGR Ab complexes illustrated that the Qdots indeed labeled iEGFR throughout the cells post VBL delivery (Figure 4D). These novel findings are the first to successfully utilize VBLs for intracellular, nanoparticle delivery, and also the first to achieve cytosolic binding of intracellular targets significant to brain cancer research and detection.

\section{Conclusions}

Intracellular delivery of functionalized nanoparticles is a critical goal for numerous biomedical applications, especially the early detection and diagnostic of malignant brain tumors. Delivery methods that enable Qdots to target specific intracellular brain cancer markers will greatly aid in the molecular labeling of tumor samples $[65,66]$, as well as in surgical imaging procedures of brain tumors $[67,68]$. The current study is the first to use Sendai virus-based carriers for cytosolic delivery of targeted nanoparticles, as well as the first to explore VBLs for the study of intracellular markers in malignant brain tumors. Results illustrate that VBLs increased the specific intracellular labeling of EGFR by $50 \%$, and, importantly, significantly bypassed Qdot entrapment within endosomes for the GBM and MB brain tumor samples studied. VBLs provide a reliable and consistent method for cytosolic delivery of nanoparticles that are targeted towards highly selective intracellular protein sequences. Further, virus-based liposomes do not only facilitate cytosolic delivery, but additionally provide the feasibility of TEM to enable precise localization of target proteins.

\section{Methods}

\section{Cell Culture}

The medulloblastoma-derived Daoy cell line (\#HTB-186, purchased from ATCC, Manassas, VA) was established from a tumor biopsy of a 4-year-old boy. The glioblastoma-derived U251 cells were a kind gift from Dr. Eric Holland (MSKCC) [55]. The cervical cancer-derived HeLa cell line (\# CCL-2 ${ }^{\mathrm{TM}}$ ) was purchased from ATCC, Manassas, VA. Daoy cells were cultured with sterile EMEM (Mediatech Inc., Herndon, VA), supplemented with 2\% LGlutamine (Mediatech Inc., Herndon, VA), 1\% PenicillinStreptomycin-Amphotericin B - 100× solution (Mediatech Inc., Herndon, VA), and 10\% fetal bovine serum (Gemini Bio-Products, West Sacramento, CA). U251 and HeLa cells were cultured with sterile DMEM (Sigma, St. Louis, MO), supplemented with $1 \%$ Penicillin-Streptomycin
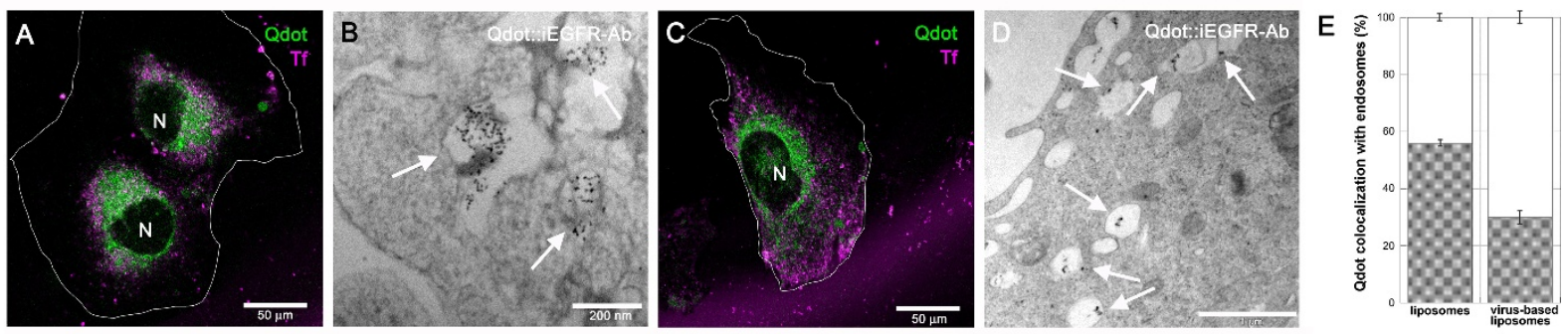

Figure 4 Delivery of Qdots, targeted and non-targeted to intracellular EGFR, by using liposomes-only and virus-based liposomes in medulloblastoma. Nuclei are denoted by the letter " $\mathrm{N}$ " and endocytic pathways are labeled by Transferrin (Tf) (green) in all confocal images. A. Double labeling of medulloblastoma (MB) cells for non-targeted Qdots (purple) delivered by liposomes-only. Scale bar equals $50 \mu \mathrm{m}$; B. TEM of MB cells treated with liposomes-only, which encapsulated Qdots functionalized with biotinylated antibodies for iEFGR (Qdot::iEFGR Ab complexes). Arrows point to clustered Qdots co-localized with endosomes. Scale bar equals $200 \mathrm{~nm}$; C. Double labeling of MB cells for nontargeted Qdots (purple) delivered by using virus-based liposomes (VBLs.) Scale bar equals $50 \mu \mathrm{m}$; D. TEM of MB cells treated with VBLs that encapsulated functionalized Qdot::iEFGR Ab complexes. Arrows point to dispersed Qdots. Scale bar equals $200 \mathrm{~nm}$. E. Measurement of Qdot colocalization with endosomes (black) and with cell cytosol (white) when delivered by liposomes-only or VBLs. 
solution (Mediatech Inc., Herndon, VA), and 10\% fetal bovine serum (Thermo Scientific HyClone, Logan, UT). The cells were grown onto sterile polystyrene tissue culture flasks (BD Biosciences, Franklin Lakes, NJ) and incubated at $37^{\circ} \mathrm{C}$ with $5 \% \mathrm{CO}_{2}$.

\section{Antibodies and Immunocytochemistry}

HeLa, medulloblastoma- and glioblastoma-derived cells grown on coverslips were fixed with paraformaldehyde (Sigma, St. Louis, MO) and labeled with biotinylated mouse antibody for iEFGR (1:500) - recognizing an internal epitope (Biodesign, Saco, ME), and goat anti-mouse AlexaFluor ${ }^{\circledR} 488$ (Invitrogen Molecular Probes, Eugene, OR). For the Qdot labeling, a solution of $5 \mathrm{nM}$ streptavidin-conjugated Qdot 655 (Invitrogen Molecular Probes, Eugene, OR)::5 nM iEGFR antibody was incubated on a shaker for 1 hour at $25^{\circ} \mathrm{C}$, and used in the immunocytochemistry after fixing. Transferrin AlexaFluor ${ }^{\circledR} 488$ or 594 conjugates (Tf) (Invitrogen Molecular Probes, Eugene, OR) were used to label the clathrin-mediated pathway: a $20 \mu \mathrm{g} / \mathrm{mL}$ solution of $\mathrm{Tf}$ was applied and incubated with the cells for 1 hour at $37^{\circ} \mathrm{C}$. After labeling, the cells were subsequently mounted in glycerol (Polyscience Inc., Warrington, PA). Each experiment was performed three times.

\section{Fluorescence Microscopy and Analysis}

Confocal laser scanning microscopy imaging was performed using a Leica TCS SP2 instrument (Leica Microsystems, Bannockburn, IL) with a $63 \times$ oil immersion objective (NA 1.4). Identical imaging conditions were used for each set of experiments. A total of 3-5 samples were prepared and three random regions were imaged per sample, three times each per experimental condition. Analysis of confocal images was performed using Matlab software (version 7.7.0.471) to import data as matrices containing absolute intensity values. Data in each matrix was thresholded at $10-15 \%$ of the maximum intensity in the respective matrix in order to eliminate background signal due to scatter. Co-localization of fluorescent labels was then defined as the exact overlapping of data points with values above the threshold value of the respective matrices. Thresholded Manders Coefficients were also calculated using NIH Image Software (NIH, Bethesda, MA) to additionally determine co-localization [69].

\section{Liposome Preparation}

Cationic lipids were purchased from Avanti Polar Lipids, Inc. (Alabaster, AL). Two milligrams each of powdered lipids 1-oleoyl-2-palmitoyl-sn-glycero-3-phosphocholine (OPPC) and 1, 2 dioleoyl-sn-glycero-3-ethylphosphocholine (DOPC+) were dissolved in chloroform at a 1:1 molar ratio in a glass vial. The lipid mixture $(1 \mathrm{mg} / \mathrm{mL})$ was aliquoted into glass vials using a Pasteur pipette and the vials were placed in a dessicator connected to a vacuum pump (Neuberger Inc., Trenton, NJ) for 2.5 to 3 hours. Inert nitrogen gas was used afterwards to flush out the dessicator before opening. The vials containing lipid sheets were placed at $-20^{\circ} \mathrm{C}$ for at least 24 hours. The lipid sheets were placed at room temperature prior to use in order to prevent condensation. The lipid sheets were hydrated with either of the following two solutions yielding in both cases liposome solutions with lipid concentration of $0.5 \mathrm{mg} / \mathrm{mL}$ : (i) PBS with $5 \mathrm{nM}$ streptavidin-conjugated Qdot 655; (ii) PBS with $5 \mathrm{nM}$ streptavidin-conjugated Qdot 655 functionalized with a biotinylated antibody for iEFGR (Biodesign, Saco, ME). The vials were vortexed for four minutes, and then subjected to 3 cycles of freezing at $-20^{\circ} \mathrm{C}$ and thawing at room temperature. After the last freeze-thaw cycle, the glass vials containing hydrated liposomes were placed at room temperature in order to prevent condensation. The sample was loaded into a $1000 \mu \mathrm{L}$ gas-tight syringe, which was placed into an Avanti Mini-Extruder (Avanti Polar Lipids, Inc., Alabaster, AL). A polycarbonate membrane with a pore diameter size of $200 \mathrm{~nm}$ was used for the extrusion.

\section{Virus-Based Liposome Preparation}

The protocol used in this work was a modified version of the Sendai virus-based protocols found in existing literature [47]. Briefly, commercial, purified Sendai viruses (Charles River, Wilmington, MA) were inactivated by exposure to $9.6 \times 105 \mu \mathrm{J} / \mathrm{cm}^{2} \mathrm{UV}$ light. Inactivated viruses were mixed with liposomes prepared as described above at a ratio of virus: liposomes $=3000 \mathrm{HAU}: 1 \mathrm{mg}$ lipid. The mixture was incubated for 10 minutes on ice to allow the viruses to dock onto the liposomes, and afterwards 1 hour at $37^{\circ} \mathrm{C}$ in a water-bath with shaking $(120 / \mathrm{min})$. After this incubation, the Sendai virus-liposome preparation was layered over a sucrose gradient (30\% sucrose over $60 \%$ sucrose in a 4:1 volume ratio; in PBS), and spun at approximately 22,000 rpm for 3 hours at $4^{\circ} \mathrm{C}$. After spinning, the virus-based liposomes were located in a layer between the PBS solution and 30\% sucrose, while unincorporated Sendai virus particles were found between the $30 \%$ and $60 \%$ sucrose layers. The virus-based liposomes were generally used immediately after preparation, or were stored at $4^{\circ} \mathrm{C}$ for up to 24 hours prior to use.

\section{Liposome- and Virus-Based Liposome Cell Incubation}

The liposomes or virus-based liposome solutions, containing either functionalized or non-targeted Qdots, were applied directly onto cells plated on coverslips. After 10 minutes incubation on ice to allow the docking of the delivery system to the cells, cells were incubated at $37^{\circ} \mathrm{C}$ for 1 hour. For the intracellular localization of nontargeted Qdots, cells were also incubated with a $20 \mu \mathrm{g} / \mathrm{mL}$ 
solution of Tf -594 conjugate for 30 minutes at $37^{\circ} \mathrm{C}$. After incubation, cells were fixed with $3.7 \%$ paraformaldehyde (Sigma, Atlanta, GA) and mounted in glycerol (Polyscience Inc., Warrington, PA).

\section{Transmission Electron Microscopy (TEM)}

For the analysis of intracellular distribution of Qdots, medulloblastoma cells cultured on collagen-coated plates were labeled with Qdot::iEFGR Ab via virus-based liposome delivery, as described above. After washing three times with PBS, the cells were fixed with $2 \%$ glutaraldehyde (Electron Microscopy Services, Hatfield, PA) for 2 hours at $4^{\circ} \mathrm{C}$ and then post-fixed with $1 \%$ osmium tetroxide (Electron Microscopy Services, Hatfield, PA) for 2 hours at $4-8^{\circ} \mathrm{C}$. After dehydration by immersing in serially diluted aqueous ethanol solutions, the specimens were embedded in epoxy resin, sectioned to $80-100 \mathrm{~nm}$ thick, stained with uranyl acetate, and examined with a Zeiss EM 902 (Carl Zeiss, Peabody, MA). As a control, non-targeted Qdots treated cells were also imaged following preparation as described above. A total of 10-15 images per sample were acquired from three different samples per experimental condition.

\section{List of abbreviations}

EGFR: Epidermal Growth Factor Receptor; GBM: Glioblastoma; MB: Medulloblastoma; Qdots: Quantum dots; TEM: Transmitted Electron Microscopy; Tf: Transferrin; VBL: Virus-Based Liposome.

\section{Acknowledgements}

We thank Dr. Paul Gottlieb and Mr. Hui Wei in the Department of Microbiology and Immunology, Sophie Davis School of Biomedical Education, The City College of New York for providing access to their facilities and technical support. We acknowledge the use of the City College of New York Electron Microscopy Facility and the help of Dr. Jorge Morales. This work was supported by funds from the National Cancer Institute CA118255 and CA143798.

\section{Authors' contributions}

VD participated in the study design and carried out the EGFR testing of cell samples, immunoassays, nanoparticle delivery and drafted the manuscript. VR carried out quantitative analysis of data images using Matlab and $\mathrm{NIH}$ Image. MV conceived of the study, participated in its design and coordination and helped to draft the manuscript. All authors read and approved the final manuscript.

\section{Competing interests}

The authors declare that they have no competing interests.

Received: 13 June 2011 Accepted: 17 February 2012

Published: 17 February 2012

\section{References}

1. Alivisatos AP, Gu W, Larabell C: Quantum dots as cellular probes. Annu Rev Biomed Eng 2005, 7:55-76.

2. Liu BR, Huang YW, Chiang HJ, Lee HJ: Cell-penetrating peptidefunctionalized quantum dots for intracellular delivery. J Nanosci Nanotechnol 2010, 10(12):7897-905.

3. Resch-Genger U, Grabolle M, Cavaliere-Jaricot S, Nitschke R, Nann T: Quantum dots versus organic dyes as fluorescent labels. Nat Methods 2008, 5(9):763-75.
4. Song $S$, Qin $Y$, He Y, Huang Q, Fan C, Chen HY: Functional nanoprobes for ultrasensitive detection of biomolecules. Chem Soc Rev 2010, 39(11):4234-43.

5. Cho DY, Lin SZ, Yang WK, Hsu DM, Lin HL, Lee HC, Lee WY, Chiu SC: The Role of Cancer Stem Cells (CD133(+)) in Malignant Gliomas. Cell Transplant 2011, 20(1):121-5.

6. Ferrari M: Cancer nanotechnology: opportunities and challenges. Nat Rev Cancer 2005, 5(3):161-71.

7. Stupp R, Hegi ME, Mason WP, van den Bent MJ, Taphoorn MJ, Janzer RC, Ludwin SK, Allgeier A, Fisher B, Belanger K, Hau P, Brandes AA, Gijtenbeek J, Marosi C, Vecht CJ, Mokhtari K, Wesseling P, Villa S, Eisenhauer E, Gorlia T, Weller M, Lacombe D, Cairncross JG, Mirimanoff RO: Effects of radiotherapy with concomitant and adjuvant temozolomide versus radiotherapy alone on survival in glioblastoma in a randomised phase III study: 5-year analysis of the EORTC-NCIC trial. Lancet Oncol 2009, 10(5):459-66.

8. Altman DA, Atkinson DS Jr, Brat DJ: Best cases from the AFIP: glioblastoma multiforme. Radiographics 2007, 27(3):883-8.

9. Yamahara T, Numa Y, Oishi T, Kawaguchi T, Seno T, Asai A, Kawamoto K: Morphological and flow cytometric analysis of cell infiltration in glioblastoma: a comparison of autopsy brain and neuroimaging. Brain Tumor Pathol 2010, 27(2):81-7.

10. Hensel T, Amberger VR, Schwab ME: A metalloprotease activity from C6 glioma cells inactivates the myelin-associated neurite growth inhibitors and can be neutralized by antibodies. $\mathrm{Br} J$ Cancer 1998, 78(12):1564-72.

11. Galli R, Binda E, Orfanelli U, Cipelletti B, Gritti A, De Vitis S, Fiocco R, Foroni $C$, Dimeco F, Vescovi A: Isolation and characterization of tumorigenic, stem-like neural precursors from human glioblastoma. Cancer Res 2004, 64(19):7011-21.

12. Ying M, Sang Y, Li Y, Guerrero-Cazares H, Quinones-Hinojosa A, Vescovi AL, Eberhart CG, Xia S, Laterra J: Kruppel-like family of transcription factor 9 , a differentiation-associated transcription factor, suppresses Notch1 signaling and inhibits glioblastoma-initiating stem cells. Stem Cells 2011 , 29(1):20-31

13. Lasky JL, Choe M, Nakano I: Cancer stem cells in pediatric brain tumors. Curr Stem Cell Res Ther 2009, 4(4):298-305.

14. Burkhardt JK, Shin BJ, Boockvar JA: Neural stem cells and glioma stem-like cells respond differently to chemotherapeutic drugs: selectivity at the cellular level. Neurosurgery 2011, 68(6):N21-2.

15. Festa M, Del Valle L, Khalili K, Franco R, Scognamiglio G, Graziano V, De Laurenzi V, Turco MC, Rosati A: BAG3 protein is overexpressed in human glioblastoma and is a potential target for therapy. Am J Pathol 2011, 178(6):2504-12.

16. Romano S, Di Pace A, Sorrentino A, Bisogni R, Sivero L, Romano MF: FK506 binding proteins as targets in anticancer therapy. Anticancer Agents Med Chem 2010, 10(9):651-6.

17. Mathieu J, Zhang Z, Zhou W, Wang AJ, Heddleston JM, Pinna CM, Hubaud A, Stadler B, Choi M, Bar M, Tewari M, Liu A, Vessella R, Rostomily R, Born D, Horwitz M, Ware C, Blau CA, Cleary MA, Rich JN, Ruohola-Baker H: HIF induces human embryonic stem cell markers in cancer cells. Cancer Res 2011, 71(13):4640-52.

18. Huang Z, Cheng L, Guryanova OA, Wu Q, Bao S: Cancer stem cells in glioblastoma-molecular signaling and therapeutic targeting. Protein Cell 2010, 1(7):638-55.

19. Schleicher SM, Thotala DK, Linkous AG, Hu R, Leahy KM, Yazlovitskaya EM, Hallahan DE: Autotaxin and LPA receptors represent potential molecular targets for the radiosensitization of murine glioma through effects on tumor vasculature. PLoS One 2011, 6(7):e22182.

20. Rognoni P, Chiarelli LR, Comincini S, Azzalin A, Miracco C, Valentini G: Biochemical signatures of doppel protein in human astrocytomas to support prediction in tumor malignancy. J Biomed Biotechnol 2010, 2010:301067.

21. Niu CS, Li DX, Liu YH, Fu XM, Tang SF, Li J: Expression of NANOG in human gliomas and its relationship with undifferentiated glioma cells. Oncol Rep 2011, 26(3):593-601.

22. Maysinger D, Lovrić J: Quantum dots and other fluorescent nanoparticles: quo vadis in the cell? Adv Exp Med Biol. 2007, 620:156-67.

23. Delehanty JB, Boeneman K, Bradburne CE, Robertson K, Medintz IL: Quantum dots: a powerful tool for understanding the intricacies of nanoparticle-mediated drug delivery. Expert Opin Drug Deliv 2009, 6(10):1091-112. 
24. Torchilin VP: Nanocarriers. Pharm Res 2007, 24(12):2333-4.

25. Xiao Y, Forry SP, Gao X, Holbrook RD, Telford WG, Tona A: Dynamics and mechanisms of quantum dot nanoparticle cellular uptake. J Nanobiotechnology 2010, 8:13.

26. Derfus AM, Chan WCW, Bhatia SN: Intracellular Delivery of Quantum Dots for Live Cell Labeling and Organelle Tracking. Advanced Materials 2004, 16(12):961-6.

27. Chen $X$, Kis A, Zettl A, Bertozzi CR: A cell nanoinjector based on carbon nanotubes. Proc Natl Acad Sci USA 2007, 104(20):8218-22.

28. Delehanty JB, Mattoussi H, Medintz IL: Delivering quantum dots into cells: strategies, progress and remaining issues. Anal Bioanal Chem 2009, 393(4):1091-105

29. Yum K, Na S, Xiang Y, Wang N, Yu MF: Mechanochemical delivery and dynamic tracking of fluorescent quantum dots in the cytoplasm and nucleus of living cells. Nano Lett 2009, 9(5):2193-8.

30. Fonseca SB, Pereira MP, Kelley SO: Recent advances in the use of cellpenetrating peptides for medical and biological applications. Adv Drug Deliv Rev 2009, 61(11):953-64.

31. Suk JS, Suh J, Choy K, Lai SK, Fu J, Hanes J: Gene delivery to differentiated neurotypic cells with RGD and HIV Tat peptide functionalized polymeric nanoparticles. Biomaterials 2006, 27(29):5143-50.

32. Akita $H$, Kogure $K$, Moriguchi $R$, Nakamura $Y$, Higashi T, Nakamura T, Serada S, Fujimoto M, Naka T, Futaki S, Harashima H: Nanoparticles for ex vivo siRNA delivery to dendritic cells for cancer vaccines: programmed endosomal escape and dissociation. J Control Release 2011, 143(3):311-7.

33. Serda RE, Mack A, van de Ven AL, Ferrati S, Dunner K Jr, Godin B, Chiappini C, Landry M, Brousseau L, Liu X, Bean AJ, Ferrari M: Logicembedded vectors for intracellular partitioning, endosomal escape, and exocytosis of nanoparticles. Small 2010, 6(23):2691-700.

34. Bale SS, Kwon SJ, Shah DA, Banerjee A, Dordick JS, Kane RS: Nanoparticlemediated cytoplasmic delivery of proteins to target cellular machinery. ACS Nano 2010, 4(3):1493-500.

35. Kim C, Agasti SS, Zhu Z, Isaacs L, Rotello VM: Recognition-mediated activation of therapeutic gold nanoparticles inside living cells. Nat Chem 2010, 2(11):962-6.

36. Taylor U, Klein S, Petersen S, Kues W, Barcikowski S, Rath D: Nonendosomal cellular uptake of ligand-free, positively charged gold nanoparticles. Cytometry A 2010, 77(5):439-46.

37. Jiang X, Rocker C, Hafner M, Brandholt S, Dorlich RM, Nienhaus GU: Endoand exocytosis of zwitterionic quantum dot nanoparticles by live HeLa cells. ACS Nano 2010, 4(11):6787-97.

38. Contreras J, Xie J, Chen YJ, Pei H, Zhang G, Fraser CL, Hamm-Alvarez SF: Intracellular uptake and trafficking of difluoroboron dibenzoylmethanepolylactide nanoparticles in HeLa cells. ACS Nano 2010, 4(5):2735-47.

39. Febvay S, Marini DM, Belcher AM, Clapham DE: Targeted cytosolic delivery of cell-impermeable compounds by nanoparticle-mediated, lighttriggered endosome disruption. Nano Lett 2010, 10(6):2211-9.

40. Krpetic Z, Nativo P, See V, Prior IA, Brust M, Volk M: Inflicting controlled nonthermal damage to subcellular structures by laser-activated gold nanoparticles. Nano Lett 2010, 10(11):4549-54.

41. Kadiu I, Nowacek A, McMillan J, Gendelman HE: Macrophage endocytic trafficking of antiretroviral nanoparticles. Nanomedicine (Lond) 2010.

42. Dudu V, Ramcharan M, Gilchrist ML, Holland EC, Vazquez M: Liposome delivery of quantum dots to the cytosol of live cells. J Nanosci Nanotechnol 2008, 8(5):2293-300.

43. Verma IM, Weitzman MD: Gene therapy: twenty-first century medicine. Annu Rev Biochem 2005, 74:711-38.

44. Chen L, Zurita AJ, Ardelt PU, Giordano RJ, Arap W, Pasqualini R: Design and validation of a bifunctional ligand display system for receptor targeting. Chem Biol 2004, 11(8):1081-91.

45. Dixit SK, Goicochea NL, Daniel MC, Murali A, Bronstein L, De M, Stein B, Rotello VM, Kao CC, Dragnea B: Quantum dot encapsulation in viral capsids. Nano Lett 2006, 6(9):1993-9.

46. Li F, Li K, Cui ZQ, Zhang ZP, Wei HP, Gao D, Deng JY, Zhang XE: Viral coat proteins as flexible nano-building-blocks for nanoparticle encapsulation. Small 2010, 6(20):2301-8.

47. Mann MJ, Morishita R, Gibbons GH, von der Leyen HE, Dzau VJ: DNA transfer into vascular smooth muscle using fusigenic Sendai virus (HVJ)liposomes. Mol Cell Biochem 1997, 172(1-2):3-12.

48. Kaneda Y: Applications of Hemagglutinating Virus of Japan in therapeutic delivery systems. Expert Opin Drug Deliv 2008, 5(2):221-33.
49. Tozawa H, Watanabe M, Ishida N: Structural components of Sendai virus. Serological and physicochemical characterization of hemagglutinin subunit associated with neuraminidase activity. Virology 1973, 55(1):242-53.

50. Homma M, Ouchi M: Trypsin action on the growth of Sendai virus in tissue culture cells. 3. Structural difference of Sendai viruses grown in eggs and tissue culture cells. J Virol 1973, 12(6):1457-65.

51. Scheid A, Choppin PW: Identification of biological activities of paramyxovirus glycoproteins. Activation of cell fusion, hemolysis, and infectivity of proteolytic cleavage of an inactive precursor protein of Sendai virus. Virology 1974, 57(2):475-90.

52. Bodey B, Kaiser HE, Siegel SE: Epidermal growth factor receptor (EGFR) expression in childhood brain tumors. In Vivo 2005, 19(5):931-41.

53. Izycka-Swieszewska E, Brzeskwiniewicz M, Wozniak A, Drozynska E, Grajkowska W, Perek D, Balcerska A, Klepacka T, Limon J: EGFR, PIK3CA and PTEN gene status and their protein product expression in neuroblastic tumours. Folia Neuropathol 2010, 48(4):238-45.

54. Nicholas MK, Lukas RV, Jafri NF, Faoro L, Salgia R: Epidermal growth factor receptor - mediated signal transduction in the development and therapy of gliomas. Clin Cancer Res 2006, 12(24):7261-70.

55. Sabharwal N, Holland EC, Vazquez M: Live cell labeling of glial progenitor cells using targeted quantum dots. Ann Biomed Eng 2009, 37(10):1967-73.

56. Dudu $V$, Rotari $V$, Vazquez M: Targeted extracellular nanoparticles enable intracellular detection of activated epidermal growth factor receptor in living brain cancer cells. Nanomedicine 2011, 7(6):896-903.

57. Zhang C, Li A, Zhang X, Xiao H: A novel TIP30 protein complex regulates EGF receptor signaling and endocytic degradation. J Biol Chem 2011, 286(11):9373-81.

58. Ying $H$, Zheng $H$, Scott $K$, Wiedemeyer R, Yan H, Lim C, Huang J, Dhakal S, Ivanova E, Xiao Y, Zhang H, Hu J, Stommel JM, Lee MA, Chen AJ, Paik JH, Segatto O, Brennan C, Elferink LA, Wang YA, Chin L, DePinho RA: Mig-6 controls EGFR trafficking and suppresses gliomagenesis. Proc Natl Acad Sci USA 2010, 107(15):6912-7.

59. Wiley HS, Herbst JJ, Walsh BJ, Lauffenburger DA, Rosenfeld MG, Gill GN: The role of tyrosine kinase activity in endocytosis, compartmentation, and down-regulation of the epidermal growth factor receptor. J Biol Chem 1991, 266(17):11083-94.

60. Bhattacharyya S, Bhattacharya R, Curley S, McNiven MA, Mukherjee P: Nanoconjugation modulates the trafficking and mechanism of antibody induced receptor endocytosis. Proc Natl Acad Sci USA 2010, 107(33):14541-6.

61. Dhar S, Kolishetti N, Lippard SJ, Farokhzad OC: Targeted delivery of a cisplatin prodrug for safer and more effective prostate cancer therapy in vivo. Proc Natl Acad Sci USA 2011, 108(5):1850-5.

62. Van de Broek B, Devoogdt N, D'Hollander A, Gijs HL, Jans K, Lagae L, Muyldermans S, Maes G, Borghs G: Specific Cell Targeting with Nanobody Conjugated Branched Gold Nanoparticles for Photothermal Therapy. ACS Nano 2011.

63. Cai W, Shin DW, Chen K, Gheysens O, Cao Q, Wang SX, Gambhir SS, Chen $X$ : Peptide-labeled near-infrared quantum dots for imaging tumor vasculature in living subjects. Nano Lett 2006, 6(4):669-76.

64. Williams D, Foye W, Lemke T: Foye's Principles of Medicinal Chemistry. Publisher: Lippincott Williams \& Wilkins; Fifth 2002.

65. Misra R, Acharya S, Sahoo SK: Cancer nanotechnology: application of nanotechnology in cancer therapy. Drug Discov Today 2010, 15(1920):842-50.

66. Yang K, Cao YA, Shi C, Li ZG, Zhang FJ, Yang J, Zhao C: Quantum dotbased visual in vivo imaging for oral squamous cell carcinoma in mice. Oral Oncol 2010, 46(12):864-8.

67. Juzenas $P$, Juzeniene $A$, lani $V$, Moan J: Depth profile of protoporphyrin IX fluorescence in an amelanotic mouse melanoma model. Photochem Photobiol 2009, 85(3):760-4.

68. Smith AM, Ruan G, Rhyner MN, Nie S: Engineering luminescent quantum dots for in vivo molecular and cellular imaging. Ann Biomed Eng 2006, 34(1):3-14.

69. Ramirez O, Garcia A, Rojas R, Couve A, Hartel S: Confined displacement algorithm determines true and random colocalization in fluorescence microscopy. J Microsc 2010, 239(3):173-83.

doi:10.1186/1477-3155-10-9

Cite this article as: Dudu et al: Sendai virus-based liposomes enable targeted cytosolic delivery of nanoparticles in brain tumor-derived cells. Journal of Nanobiotechnology 2012 10:9. 